ISSN: 2362-1303 (Paper) | eISSN: 2362-1311(Online)

JOURNAL OF ADVANCED ACADEMIC RESEARCH (JAAR)

July 2015

\title{
Characteristics of Morbidity and Choice of Health Care Facilities in Nepal
}

\author{
Arjun Kumar Thapa ${ }^{1}$ \& Dr. Shiva Raj Adhikari ${ }^{2}$ \\ ${ }^{1}$ PhD Scholar | Mewar University, Rajasthan, India \\ ${ }^{2}$ Assot. Professor | Tribhuvan University, Kathmandu Nepal | sssadhikari@ gmail.com
}

\section{Corresponding Author}

Arjun Kumar Thapa

yogirajarjun@gmail.com

\section{ABSTRACT}

In aftermath of People's Movement 2008, the Government of Nepal promulgated health as a component of basic human rights. But Nepalese health consumers can seek health care services in government primary health facilities, hospitals, private clinics or do self-medication. The study intends to describe the characteristics of morbidity and factors associated in choosing particular type of health facility. For data, the study depends on a nationally representative rich cross sectional household survey data (Nepal Living Standard Survey, 2010/11) of Nepal. The findings of the study show that around one fifth of the total population reported acute illness while near about 10 percent is facing chronic illness. Around 30 percent of people reporting acute illness do not seek any health care services. Most of the rural people and poor population seek health care services in government primary health care facilities and private pharmacies. People belonging to low income quintiles are likely to seek health care services in government primary facilities. Similarly people residing in mountain \& hill are likely to utilize services of government primary facilities. The study shows that urbanites are more likely to seek services in hospitals and private clinics. Therefore a homogeneous health care service production and delivery cannot address the country wide demand of health care services.

\section{KEY WORDS}

Health, Health Facilities, Health Seeking

\section{BACKGROUND}

Good health, as people know from their own experience, is a crucial part of well-being and socioeconomic development. From the economic viewpoint, improved health contributes to growth in many ways. The government has a vital role and obligation ensure basic primary health care services. The study of health service production and demand analysis are part and parcel of development thinking. In the same limelight, the amalgamation of health as a subject matter with economic tools of analysis is gaining new researching platform.

Grossman (1972) developed inter-temporal utility model, which is based on the household production framework. His study is regarded as pioneer to introduce the concept that 
ISSN: 2362-1303 (Paper) | eISSN: 2362-1311(Online)

JOURNAL OF ADVANCED ACADEMIC RESEARCH (JAAR)

July 2015

consumers do not demand medical care per se, but it is a derived demand generated through the demand for health. Thence forth the health care utilization topics gained momentous interest among the health economists and public policy makers.

The determination of demand for health care indicates the policy makers regarding the role of consumer awareness and knowledge in improving the utilization of highly cost-effective health interventions or health services (Adhikari, 2013). Moreover the demand for health care services and availability, access ability and affordability are important for those who cannot afford to purchase them. The World Health Organization (WHO) estimates that about 1.3 to 2.1 billion people are without access to essential medicines (WHO, 2004a).

Achieving UC access to health care has remained as one of the major bottlenecks for The Government of Nepal. To address this concern, the government adopted a Free Health Care program (FHCP) as a risk protection scheme and is providing universal free medicine to primary level facilities of the public health system since 2008 (RTI, 2010).

The households in low-income countries spend a significant portion of their resources on remedial health care. Banerjee et al. (2009) found that out-of-pocket health expenditure represents about $10 \%$ of total household expenditure among slum dwellers in Hyderabad, India. Using detailed diaries kept by rural households in western Kenya, Dupas \& Robinson (2009) also found that health expenditure represents $8 \%$ of total household expenditure.

As per latest Nepal Living Standard Survey report more than sixty percent of people seek health care services in private facilities while around a fifth go to government primary facilities where the services are free (NLSS, 2010/11). Another study by Karkee \& Jha also show that people seeking health services for acute illness in government facilities account to only 44 percent (Karkee \& Jha, 2010). In the recent years there is huge growth of private hospitals and nursing homes besides around 10000 private pharmacies been operated in the country. The findings of the same study indicate that people are attracted for better counseling, quicker service delivery and availability of medicines there.

Paudel et al., (2012) concluded that only one third of the study population received government health services. The reason for inaccessibility of basic health services was lamented to distance of travel, unavailability of health staffs and odd timings of service availability in their study of Surkhet (Paudel et al., 2012).

Adhikari (2013) concludes that FHCP has positive impact on health coverage and service utilization by the targeted population and had ensured equity in health service utilization. But he concludes that out of pocket expenditure and catastrophic payment still exists. Despite extensive outreach of public health system in rural and remote areas, the distribution of financial protection and access to health care did not improve much. A considerable portion of population is still seeking health services in private facilities.

This study intends to describe the characteristics of morbidity and assess the association the relationship between socio-demographic factors and choice of health facility.

The objectives of the study were to describe the characteristics of morbidity in Nepal and assess the association between socio-demographic factors and type of health facilities visited. 
ISSN: 2362-1303 (Paper) | eISSN: 2362-1311(Online)

JOURNAL OF ADVANCED ACADEMIC RESEARCH (JAAR)

July 2015

\section{METHOD}

\section{Study Design}

The study intended to describe the pattern in health service utilization. The services provided by all health production units or health care suppliers are weak substitutes. It depends on cross sectional secondary data. The study applied in this research was descriptive cross sectional study design. The required data for this study was extracted from Nepal Living Standard Survey (NLSS III) raw data, a nationally representative rich data. The survey includes information on socio demographic and health information of the household. The decision to seek care from government primary facility, hospital, private clinic or private pharmacy/ traditional medication is dependent variable. For comparative study and causal relational studies chi square test was used as most of the attributes are of qualitative nature. It relies on cross sectional data of NLSS III.

\section{Sampling Design and Sample Size}

Nepal Living Standard survey (NLSS III) followed the Living Standards Measurement Survey (LSMS) methodology developed and promoted by the World Bank just like previous surveys. In this study a total of 7,020 households were enumerated which comprised a total of 28747 individual. But the information was extracted regarding 5518 individuals who reported being suffering from acute illness in the last month from the day of survey. So the sample size of the sample is 5518. The basic unit of study is primarily an individual.

\section{Data presentation and analysis}

The major thrust of this study is to identify the major determinants of health seeking behaviors of Nepalese society. The analysis of health seeking or demand for health involves both supply side and demand side health system. The supply side components are health infrastructures, health human resources, medicine supply and availability and spatial access. In case of our type of health system, health inputs and health services are produced and supplied by both public and private providers. In our study, type of health facility and health providers is considered.

\section{RESULT \& DISCUSSION}

\subsection{Characteristics of Illness in Nepal}

In broad the diseases are categorized into i) chronic illness and ii) acute illness. Acute diseases are those conditions in which the peak severity of symptoms occurs within three months (usually sooner), and recovery in those who survive is usually complete. Chronic diseases or conditions are those in which symptoms continue longer than three months and in some cases for the remainder of the person's life. 
ISSN: 2362-1303 (Paper) | eISSN: 2362-1311(Online)

JOURNAL OF ADVANCED ACADEMIC RESEARCH (JAAR)

July 2015

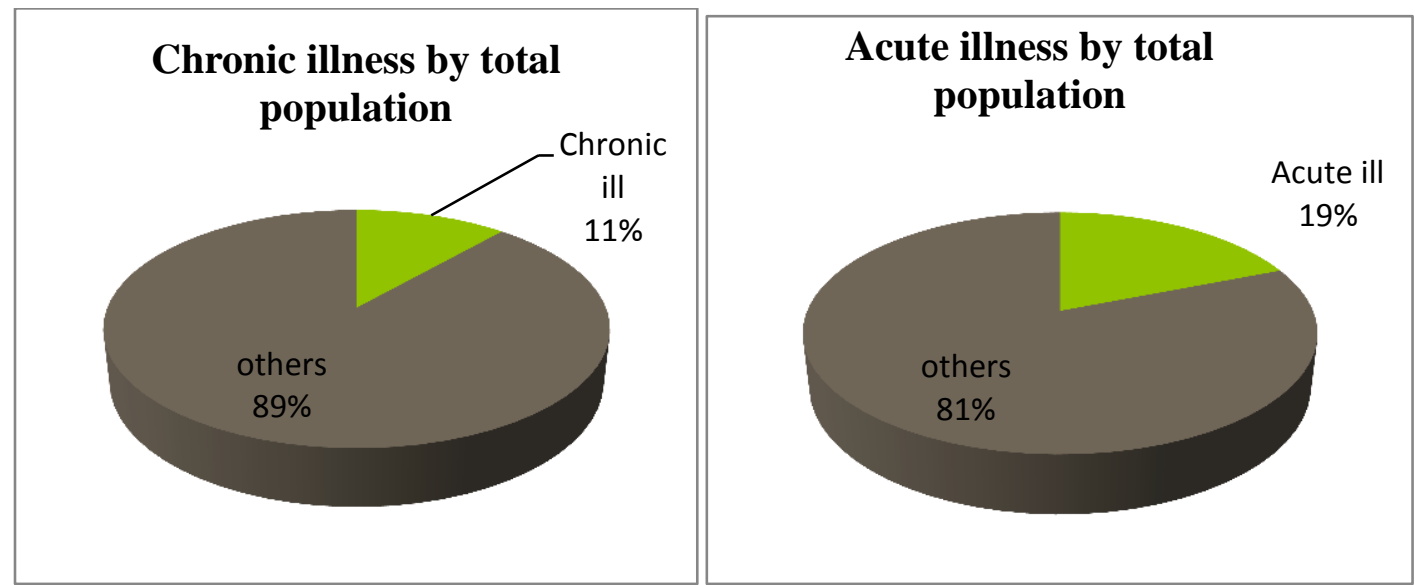

Figure 1\&II: Chronic and Acute Illness

Recovery is slow and sometimes incomplete. Overall incidence of chronic illness is 11.8 percent. Nearly a fifth of the population is suffering from acute illness. The NLSS III had one of the question regarding health of individual members of the household pertaining to acute illness. The household was asked whether any member(s) of household was ill or injured during past 30 days period. Around 19 percent of the people had one of the diseases or met with an injury.

\subsection{Major Diseases / Illness or Injuries}

Of all individuals with chronically ill 31 percent reported gastrointestinal and kidney/liver problem, 15 percent rheumatism, 11 percent $\mathrm{H} / \mathrm{L}$ blood pressure, 10 percent asthma, 6 percent heart conditions, 5 percent diabetes and 3 percent respiratory, and one percent reported epilepsy.

Table 1: Chronic and Acute Illness

\begin{tabular}{lcclccc}
\hline Chronic illness & Number & $\mathbf{\%}$ & \multicolumn{1}{c}{ Acute Illness } & Number & $\boldsymbol{\%}$ \\
\hline Heart related & 187 & 5.72 & Diarrhea & 865 & 15.68 \\
\hline Respiratory & 99 & 3.03 & Dysentery & 93 & 1.69 \\
\hline Asthma & 330 & 10.1 & Respiratory problems & 137 & 2.48 \\
\hline Epilepsy & 42 & 1.29 & Malaria & 71 & 1.29 \\
\hline Cancer & 7 & 0.21 & Cold/fever/flu & 1,713 & 31.04 \\
\hline Diabetes & 202 & 6.18 & Other fever & 1,234 & 22.36 \\
\hline Kidney/liver diseases & 46 & 1.41 & Skin disease & 109 & 1.98 \\
\hline Rheumatism related & 467 & 14.29 & Tuberculosis & 6 & 0.11 \\
\hline Gynecological problems & 140 & 4.28 & Measles & 10 & 0.18 \\
\hline Occupational illnesses & 14 & 0.43 & Jaundice & 30 & 0.54 \\
\hline High/low blood pressure & 400 & 12.24 & Parasites & 19 & 0.34 \\
\hline Gastrointestinal diseases & 894 & 27.36 & Injury & 281 & 5.09 \\
\hline Other & 440 & 13.46 & Other & 950 & 17.22 \\
\hline Total & 3,268 & 100 & & 5,518 & 100 \\
\hline Source: & & & & &
\end{tabular}

Source: CBS, 2010/11

Vol. 2. No. II

www.phdcentre.edu.np 
ISSN: 2362-1303 (Paper) | eISSN: 2362-1311(Online)

JOURNAL OF ADVANCED ACADEMIC RESEARCH (JAAR)

July 2015

Acute illness observed as any illness or injury self reported during the last 30 days. The main illness reported by the respondents under this category were cold / flu fever, other fever, diarrhea / dysentery, which occupy $31 \%, 22 \%$ and $17 \%$ respectively. Then, malaria, TB, measles, jaundice, skin diseases and dental diseases lumped up together constitutes around 5 percent of main cause of acute illness. The other category of illness also constitutes around 16 percent. Injury is reported as $5 \%$ of total cause of total ill/sickness as per NLSS III.

\subsection{Consultation of Acute Illness}

Then a follow up question was asked if they had consulted anyone or somewhere. From the figure, nearly a third did not seek anyone's advice or treatment. It is still a grave concern that even after implementation of free primary health care services a significant portion of population is deprived of health care services. The difficult topography, distance to the health facilities, unavailability of health human resources at the time of clients approaching to the facilities, poverty are some of the major hurdles of low service utilizations. Figure 3 indicates the reason

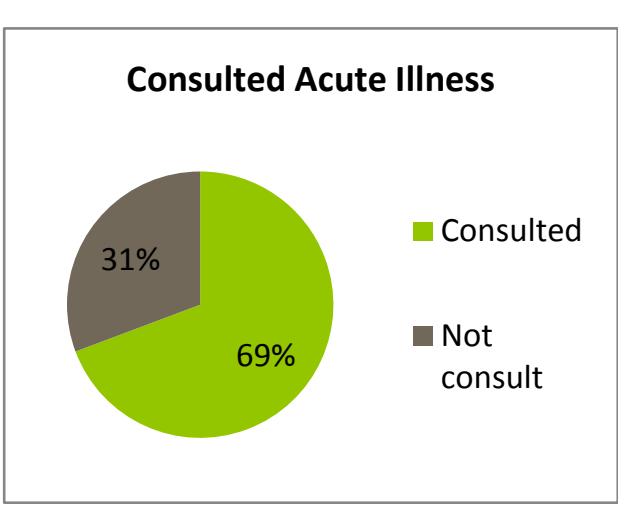

Figure 2: Consultation for not consulting illness or injury. If illness / injury not serious category is kept aside then the main reasons are too far distance health facility, too expensive health care, lack of quality health care, unavailability of health providers are major.

According to the given table around eighty percent of respondents did not consult anyone because they considered their illness or injury to be not serious or minor.

We can see from the given figure that around 5 percent of the population did not seek health care services because of distance to the facility. As indicated by various studies, distance is an important supply side constraint for health service utilization. The other important reasons are health care expenses and quality of care, 3.6 and 1.06 percent respectively. It means the coverage by government facilities are still beyond the larger population or the quality of services is too high for common and poor. The plight of health seeker is surrounded by dilemma of accessibility, availability and efficacy. Lastly the health seekers lament absenteeism, and lack of transparency on the part of health

\begin{tabular}{lcc}
\multicolumn{3}{l}{ Table 2: Reason For Not Consulting } \\
\hline Reason not consulting & Freq. & Percent \\
\hline Illness/injury not serious & 1,372 & 80.94 \\
\hline Health facility too far & 82 & 4.84 \\
\hline No transport facility & 9 & 0.53 \\
\hline Health care too expensive & 61 & 3.6 \\
\hline Health workers unfriendly & 3 & 0.18 \\
\hline Health workers not present & 10 & 0.59 \\
\hline Health care not good quality & 18 & 1.06 \\
\hline Other & 140 & 8.26 \\
\hline Total & 1,695 & 100 \\
\hline
\end{tabular}

Source: CBS, 2010/11 unfriendly behavior providers as other 
ISSN: 2362-1303 (Paper) | eISSN: 2362-1311(Online)

JOURNAL OF ADVANCED ACADEMIC RESEARCH (JAAR)

July 2015

reasons. These allegations time and again are reported about the publicly provided health systems.

\subsection{Socio-Demographic Factors and Acute Illness}

The reported acute morbidity is higher (31percent) among children less than 5 years age and 60 years above ( 22 percent) age group than other age groups. This indicates that children and adult population are more prone to illness and injury. The need for medical services is high among this population. Statistically, there is a significant association between illness and age of the respondents (Pearson chi2 $(1)=24.2808 \operatorname{Pr}=0.000)$. The percentage of Morbidity decreases with increase in family size. The chi square test shows significant association between reported morbidity and family size (Pearson chi2 $(2)=69.7537 \operatorname{Pr}=0.000$ ).

The percentage illness by caste and ethnicity ranges within 17 to 23 percent but statistically there is strong association between morbidity and caste ethnicity (Pearson chi2 (5) $=35.6133 \mathrm{Pr}=0.000)$. Even though the reported morbidity based on income quintile also ranges with 17 to 22 percent but statistically the association is significant (Pearson chi2 $(4)=$ $75.9800 \operatorname{Pr}=0.000)$.

\begin{tabular}{|c|c|c|c|}
\hline \multirow{2}{*}{ Variable } & \multirow{2}{*}{ Category } & Illness & No illness \\
\hline & & $\%(N=5518)$ & $\%(\mathrm{~N}=22956)$ \\
\hline \multirow{2}{*}{ Sex } & Male & 19 & 81 \\
\hline & Female & 19 & 81 \\
\hline \multirow{4}{*}{$\mathrm{Age}^{* * *}$} & 0 to 5 & 31 & 69 \\
\hline & 6 to 14 & 17 & 83 \\
\hline & 15 to 59 & 17 & 83 \\
\hline & $60 \&$ above & 22 & 78 \\
\hline \multirow{4}{*}{$\begin{array}{l}\text { Family } \\
\text { size }^{* * *}\end{array}$} & 1 to 2 & 28 & 72 \\
\hline & 3 to 4 & 22 & 78 \\
\hline & 5 to 6 & 19 & 81 \\
\hline & $7 \&$ above & 16 & 84 \\
\hline \multirow{6}{*}{$\begin{array}{l}\text { Caste/ } \\
\text { ethnicity*** }\end{array}$} & Upper caste hill & 19 & 81 \\
\hline & Janajatis/ethnic & 19 & 81 \\
\hline & Dalit hill & 22 & 78 \\
\hline & Upper caste Terai & 17 & 83 \\
\hline & Middle caste Terai & 21 & 79 \\
\hline & Dalit terai & 23 & 77 \\
\hline \multirow{4}{*}{$\begin{array}{l}\text { Income } \\
\text { quintile*** }\end{array}$} & Lowest $20 \%$ & 17 & 83 \\
\hline & 2nd lowest & 20 & 80 \\
\hline & 3rd quintil & 22 & 78 \\
\hline & 4th quintil & 21 & 79 \\
\hline
\end{tabular}

Vol. 2. No. II

www.phdcentre.edu.np 
ISSN: 2362-1303 (Paper) | eISSN: 2362-1311(Online)

JOURNAL OF ADVANCED ACADEMIC RESEARCH (JAAR)

\begin{tabular}{|l|l|c|c|}
\hline & Upper 20 & 18 & 82 \\
\hline \multirow{3}{*}{ Belt*** } & Mountain & 18 & 82 \\
\cline { 2 - 4 } & Hill & 18 & 82 \\
\cline { 2 - 4 } & Terai & 22 & 78 \\
\hline \multirow{2}{*}{ Region*** } & Urban & 17 & 83 \\
\cline { 2 - 4 } & Rural & 20 & 80 \\
\hline
\end{tabular}

Source: $C B S, 2010 / 11$

Contrary to general facts, this study shows that morbidity increases with increase in income quintile up to $4^{\text {th }}$ highest quintile. There is higher ( 22 percent) morbidity in Terai than in mountain or hill region. The chi square test shows significant association between Illness and ecological belts (Pearson chi2 $(2)=69.7537 \operatorname{Pr}=0.000$ ). Among the rural and urban strata, reported acute illness is higher among rural population $(20 \%)$.

As generally accepted, morbidity is higher in rural region (20 percent) than urban region. The test shows a significant association between region and illness (Pearson chi2 $(1)=$ $32.8936 \operatorname{Pr}=0.000)$.

\subsection{Place of Health Service Seeking}

The persons who reported being injured or sick within the last thirty days were asked about their place of visits. It has been categorized into public primary facilities (SHP, HP, PHC \& Mobile clinics), Public and private hospitals, Private Clinics \& private pharmacies and traditional and others.

\begin{tabular}{|l|l|l|l|l|l|}
\hline Table 4: Choice of Health Facility \\
\hline Factors & Category & Primary pub & Hospital & P Clinic & self \& other \\
\hline Sex & Male(N=1775) & 22.14 & 18.14 & 29.86 & 29.86 \\
\hline \multirow{2}{*}{$\begin{array}{l}\text { Caste/ } \\
\text { ethnic*** }\end{array}$} & Female(N=2048) & 24.17 & 19.78 & 27.34 & 28.71 \\
\cline { 2 - 6 } & Hill upper(N=1225) & 26.69 & 22.86 & 28.49 & 21.96 \\
\cline { 2 - 6 } & Janajati/ethnic (N=666) & 21.92 & 24.02 & 28.38 & 25.68 \\
\cline { 2 - 6 } & Upper terai(N=386) & 25.65 & 12.18 & 29.79 & 32.38 \\
\cline { 2 - 6 } & Mid cast teri(N=915) & 15.52 & 13.55 & 29.18 & 41.75 \\
\cline { 2 - 6 } & Dalits(N=631) & 27.58 & 18.38 & 26.94 & 27.10 \\
\hline Belt**** & Mountain(N=220) & 32.73 & 31.82 & 8.18 & 27.27 \\
\hline \multirow{2}{*}{$\begin{array}{l}\text { Urban } \\
\text { rural } * * *\end{array}$} & Hill(N=1682) & 30.56 & 19.50 & 24.97 & 24.97 \\
\hline Non/poor*** & Terai(N=1921) & 15.72 & 17.13 & 33.94 & 33.21 \\
\hline & Urban(N=1088) & 5.15 & 32.72 & 38.33 & 23.81 \\
\cline { 2 - 6 } & Non poor(N=3055) & 21.70 & 13.56 & 24.61 & 31.41 \\
\hline \multirow{2}{*}{ Source: } & Poor(N=768) & 29.30 & 15.10 & 22.01 & 33.59 \\
\hline
\end{tabular}

Source: $C B S, 2010 / 11$ Note: *** significant at $1 \%$ 
ISSN: 2362-1303 (Paper) | eISSN: 2362-1311(Online)

JOURNAL OF ADVANCED ACADEMIC RESEARCH (JAAR)

July 2015

The decision to choose a health facility is not affected by sex of the respondent which is evident from the slight differences in percentages. Statistically also there is no association between sex and decision to choose health provider. The association between caste/ethnicity, belt, region and economic status (poor non poor) are statistically significant. The demand for primary public facilities is higher among people residing in mountains and hills (around 33 and 31 percent), and rural poor ( 29 percent). The urbanites (around 33 percent) and mountain dwellers (32 percent) seek health care services in hospitals.

The majority of urbanites (38 percent), Terai dwellers (34 percent) and non-poor (30 percent) seek health care services in private clinics. The tendency of self-medication from private pharmacy and self-medication is highest among middle caste Terai and poor people.

\section{CONCLUSION}

The main objective of the study was to know the main characteristics of morbidity, health seeking behavior and also to identify the major determinants of choosing a particular type of health facility. As said around a fifth of the population reported to having some type of illness or injury within the last 30 days. Among the morbid population, a third did not seek any health care services. The reason for not seeking health by majority of the respondents perceived the illness or injury to be minor or insignificant while around a tenth did not seek health services because of distance to the facility, expensive treatment, low quality of services and bad behavior of health personals. The most common acute illnesses in Nepal are cold/ fever/flu, other fever and diarrhea/dysentery. Morbidity is more prevalent among lower age and old age population, while morbidity proportions declined with increase in family size. As was expected, acute illness was more prevalent among Dalits. Similarly, from spatial and locational view, Terai and rural parts have highest cases of acute illness in comparison to other belt and region.

The rural people, people from lower strata, people with lower educational level (Fathers education as proxy) seek health care services in government primary facilities. But majority of people from poor and non-poor category seek health care services in private pharmacies and private clinics combined. It indicates growing role of private sectors in health system of Nepal. But fairly larger proportions of non-poor seek health care services in Hospitals and private clinics than poor which signifies, both quality consciousness and ability to pay capacity of nonpoor. Similarly, a majority of non-poor consult with private and public doctors, while most of the poor people depend on government paramedics or do not seek health care/self-medicate.

\section{REFERENCES}

Adhikari, S.R. (2011). A Methodological Review of Demand Analysis: An Example of Health Care Services. Economic Journal of Development Issues Vol. 13 \& 14 No. 1-2 (2011) Combined Issue.

Vol. 2. No. II

www.phdcentre.edu.np 
ISSN: 2362-1303 (Paper) | eISSN: 2362-1311(Online)

JOURNAL OF ADVANCED ACADEMIC RESEARCH (JAAR)

Adhikari, S.R. (2013). Choices of health care financing schemes for resource poor country: An analysis of Nepal's experiences. Health 5 (2013) 1295-1302.

Adhikari, S.R. \& Maskay, N.M. (2004). Health sector policy in the first decade of Nepal's Multiparty democracy. Does clear enunciation of health priorities matter? ELSEVIER, Health Policy 68 (2004) 103-112.

Banerjee, A., Esther, Du.O., Glennerster, R., \& Kinnan, C. (2009). 'The Miracle of Microfinance? Evidence from a Randomized Evaluation' mimeo, MIT.

Dupas, P. and Robinson, J. (2009). Savings Constraints and Microenterprise Development: Evidence from a field experiment in Kenya. NBER Working Paper 14693.

Grossman, M. (1972). On the concept of health capital and the demand for health. Journal of Political Economy, 80:223-255.

-- (2000). Health human capital model. Handbook of Health economics, Culyer and Newwhouse (Ed). ELSEVIER, New York.

Karkee, R \& Jha, N. (2010). Primary Health Care Development: Where is Nepal after 30 Years of Alma Ata Declaration?. Journal of Nepal Medical Association, 2010 49(178: 178-84.

Leibowitz, A. A. (2004). The demand for health and health concerns after 30 years. Journal of Health Economics, 23: 663-671.

Paudel, R. Upadhyaya, T. \& Pahari, D.P. (2012). People's Perspective on Access to Health Care Services in a Rural District of Nepal. Journal of Nepal Medical Access 2012; 52(185); 204.

RTI International (2010). Health System Performance. Research Triangle Park, NC, USA.

Srivastav, D. (2011). An Analysis of the determinants of access to medicines and health care in developing country settings. PhD Thesis, Department of Social Policy, London School of Economics, Sept 2011.

Wagstaff, A. (1993). The demand for health: An empirical reformulation of the Grossman model. Health Economics, 2:189-198.

WHO (2004). The World Medicines Situation. Geneva, World Health Organization. 